\title{
Correction to: Effect of the Neurofeedback-EEG Training During Physical Exercise on the Range of Mental Work Performance and Individual Physiological Parameters in Swimmers
}

\author{
Mirosław Mikicin ${ }^{1}$ (D) . Anna Mróz ${ }^{1} \cdot$ Magdalena Karczewska-Lindinger ${ }^{2,3} \cdot$ Karolina Malinowska $^{1}$. \\ Andrzej Mastalerz ${ }^{1} \cdot$ Marek Kowalczyk $^{1}$
}

Published online: 27 April 2020

(c) The Author(s) 2020

\section{Correction to: Applied Psychophysiology and Biofeedback https://doi.org/10.1007/s10484-020-09456-1}

The original version of the article unfortunately contained an error in the co-author details such as family name and e-mail address.

The co-author name is Magdalena Karczewska-Lindinger but instead published incorrectly as Magdalena Karczewska and the correct e-mail address is magdalena.karczewskalindinger@gu.se.

The original article has been corrected regarding coauthor name. However, because it is a belated author correction, the e-mail address cannot be updated in the original article. It is correctly listed here in this Correction.

The original article can be found online at https://doi.org/10.1007/ s10484-020-09456-1.

Mirosław Mikicin

miroslaw.mikicin@awf.edu.pl

Anna Mróz

anna.mroz@awf.edu.pl

Magdalena Karczewska-Lindinger

magdalena.karczewska-lindinger@gu.se

Karolina Malinowska

kmalinowska.awf@op.pl

Andrzej Mastalerz

andrzej.mastalerz@awf.edu.pl

Marek Kowalczyk

m.kowalczyk@awf.edu.pl

1 Józef Piłsudski University of Physical Education, Marymoncka 34, 00-968 Warsaw, Poland

2 Department of Molecular and Clinical Medicine, Institute of Medicine, University of Gothenburg, Gothenburg, Sweden

3 Center for Health and Performance, Department of Food and Nutrition and Sport Science, University of Gothenburg, Gothenburg, Sweden
Publisher's Note Springer Nature remains neutral with regard to jurisdictional claims in published maps and institutional affiliations. 